\title{
HELICAL GEAR DESIGN FOR BENDING FATIGUE
}

\author{
Edward. E. Osakue ${ }^{1}$, Lucky Anetor ${ }^{2}$ \\ ${ }^{I}$ Department of Industrial Technology, Texas Southern University, Houston, Texas, USA \\ ${ }^{2}$ Department of Mechanical Engineering, Nigerian Defence Academy, Kaduna, Nigeria
}

\begin{abstract}
A bending stress capacity model explicit in the representation of helical gear design parameters is developed. The model accounts for the bending stresses from both tangential and axial loads on the gear tooth as well as the direct shear stresses from these loads. A shear stress concentration factor is incorporated to account for the geometric influence of the fillet at the root of the gear. The model clearly reveals the direct influence of the base helix angle on the bending stress and normal module size estimates. Several design examples of bending stress estimates from different references are computed using the new bending stress capacity model and compared with American Gear Manufacturers Association (AGMA) estimates. The examples considered cover a wide range of the helix angles which spans $15^{\circ}$ to $41.41^{\circ}$ and different normal pressure angles of $20^{\circ}$ and $25^{\circ}$. In the examples considered, the shear stress contribution to the total root bending stress varies from about $24 \%$ to $36 \%$. This is quite significant, so that ignoring it may result in early failure of helical gears in bending fatigue. The percentage variances between the new model and AGMA bending stress estimates are within -7\% to 10\% in this study. Therefore the results show very favorable comparisons with AGMA model. The new model appears to give slightly higher bending stress values in general so that for preliminary design, it offers the advantage of providing conservative solutions. The bending stress capacity model was modified for design sizing and its application is demonstrated in Example 6. The model may be used for bending fatigue design of spur gears if the helix angle is taken as $0^{\circ}$.
\end{abstract}

Keywords: Service Load Factor, Bending Fatigue Strength, Helix Angle, Base Helix Angle

\section{INTRODUCTION}

A gear is a toothed disk used to transmit power and motion when mounted on a rotating shaft. In most applications, it is made separate from the shaft but it could be made integral with the shaft, especially when it is small in size. Gear types include spur, single helical, double helical, straight bevel, spiral bevel, hypoid, and worm gears [1]. A gearset is a pair of gears coupled together in a mesh and the smaller gear is generally called "pinion" while the larger gear is called "gear" or "wheel". When smooth, slip-free uniform motion, light weight, high speed, high efficiency, precise timing, and compact design are important power drive design criteria, in nearly all cases, an appropriate system of gears can be selected to meet the needs [2].

A helical gear has teeth helically wrapped like a screw on its pitch cylinder though the pitch surfaces are cylindrical as in spur gears [3]. The helix may be right-handed or left-handed and its inclination to the axial direction is called the helix angle. A spur gear may be treated as a helical gear with a zero helix angle [2]. Helical gears can be used to transmit torque and rotational motion between parallel and nonparallel shafts, though the former is more common than the later. The initial contact in a mesh is a point which develops into a diagonal line on the tooth face as the teeth come into more engagement. This leads to a more gradual engagement of meshing teeth which results in a smoother transfer of load from the driving teeth to the driven teeth. Therefore helical gears have the ability to transmit heavy loads at high speeds [4] and run quieter and with less vibration compared to spur gears. They accommodate small variations in center distance and pitch velocity normally can be over $50 \mathrm{~m} / \mathrm{s}$. Due to the helix angle, helical gears exert axial load on supporting shafts in addition to the tangential and radial loads experienced by spur gears. When two or more single helical gears are mounted on the same shaft, the hands of the helix angles on the gears should be selected so as to minimize the axial thrust load on the shaft [4]. The helix angle has the same value for the pinion and the gear in a helical gearset. For parallel shaft assembly, the hand of the helix angle is opposite on the meshing gears but can be the same for non-parallel shafts. The range of the helix angle is between $5^{\circ}$ to $50^{\circ}[5,6]$. Helix angles of $5^{\circ}$ to $25^{\circ}$ are generally used in single-helix gears so as to keep thrust load relatively small $[5,7,8]$. For singlehelix gears, the helix angle should not exceed $30^{\circ}$ to avoid excessive axial thrust and it should not be less than $8^{\circ}$ because the advantages of helical gearing become marginal at low helix angles [7]. Thrust loads are practically eliminated in double-helix gears because of the opposing hands of the helix angles on the two faces of the gear. They develop opposite thrust reactions that tend to cancel the axial load components [4]. The helix angle for double-helix gears is generally between $20^{\circ}$ to $45^{\circ}[3,5]$. A helix angle of at least $30^{\circ}$ is recommended but a value of about $35^{\circ}$ is preferred [4, 9]. The design of double-helix gears is the same as that of single-helix gears after the transmitted power is halved [8]. It is desirable to have whole number helix angle because it simplifies machine setup for cutting and finishing helical gears [7], thereby reducing manufacturing costs.

Several potential failure modes in gearing have been identified [7, 10], but the two prominent modes are surface fatigue or pitting and bending fatigue $[2,11,12]$. This study 
is concerned only with bending fatigue. Fatigue failures are often caused by tensile stresses, so compressive stresses tend to enhance fatigue resistance [3]. In 1892, the Philadelphia Engineers club recognized Wilfred Lewis presentation on bending fatigue gear failure [13] which still serves as the basis for gear bending fatigue design today. He modeled a gear tooth as a short cantilever beam with the transmitted load applied near the tip of the gear tooth. The maximum tensile stress occurs at the root radius on the loaded or active side of the gear tooth. Depending on the geometry of the gear tooth and the characteristics of loading, the stress concentration at the root radius at the region of maximum tensile stress may vary from 1.4 to 2.5 [14]. Due to repeated loading of a gear tooth, this region becomes the preferential site for initiation of fatigue crack. Several factors may be attributed to bending fatigue failure and include poor gear design, improper assembly, misalignment of gears, overloads, inadvertent stress raisers, subsurface defects, and use of incorrect materials and heat treatments [15]. If bending fatigue failure mode is the main failure problem, the minimum number of teeth on the pinion that avoids interference will give the strongest gearset. Generated spur gears should have at least 17 teeth on a pinion to avoid undercutting of tooth profile.

Most gears available today have surface hardness in the range of $235 \mathrm{HVN}$ to $700 \mathrm{HVN}$. Medium hard gears of 235 HVN to 375 HVN hardness are generally more compliant and tolerate operational errors relatively more than hard gears [5]. They tend to generate more noise when gear failure is impending. Very high kilowatt power drives in many cases require very hard or case-hardened gears so as to keep operating pitch point velocity within allowable limits. Very hard gears are prone to scoring due to operational high load intensity and sliding velocities [5]. Gear tooth form accuracy for high speed gearing has to be very good in order to minimize internally generated dynamic loads [16]. Thruhardened gears (160 HVN to $450 \mathrm{HVN}$ hardness) have the same hardness at the surface and core and bending fatigue failure is more likely to initiate from the surface at the gear root where the induced bending stress is highest. Casehardened gears surface hardness is in the range of $450 \mathrm{HVN}$ to $1000 \mathrm{HVN}$ and their core hardness is substantially lower than the surface hardness. This means the bending fatigue strength of the gear root surface can be higher than that of the core. Therefore, bending fatigue failure may occur at the transition between case-hardness and core-hardness if the induced stress at the junction is more than the available core fatigue strength. Case-hardened gears are therefore prone to bending fatigue failure at the core.

Helical gears are increasingly being used because of their relatively smooth and quiet operation, large load carrying capacity, and higher operating speed [5, 17]. Single-helix and double-helix gears are mainly used for high speed gearing in parallel shaft connection and other types of gears are seldom used for high speed applications. Single-helix gears can be used for pitch point speed of up to $50 \mathrm{~m} / \mathrm{s}$ while double-helix gears may be used up to $150 \mathrm{~m} / \mathrm{s}$ pitch point speed [18]. But high speed gearing has presented some challenges both to designers and manufacturers [5]. Therefore a better understanding of the loading and analysis of the elements and transmission process in gearing can help in addressing these challenges. Similarly, developing suitable design analysis methods that can be easily applied in practice are necessary in order to maximize the benefits of helical gear transmission in particular and gears in general. Particularly, relatively accurate simplified design analysis methods help to shorten design and development times and thus reduce design project costs. This work is done with the purpose of providing a relatively accurate simplified design analysis methods for helical gears based on bending fatigue. The power loss per mesh in cylindrical gear drives is of the order of $1 \%$ [19] which is considered negligible in this study.

\subsection{Helical Gear Forces and Planes}

Fig. 1 shows the forces on a helical gear tooth at the pitch point on the pitch cylinder. The coordinate axes are set with the pitch point as origin. The driving force is the tangential force $F_{x}$, which is created in the transverse plane. The force $F_{n}$ determines the contact stress while $F_{N}$ determines the bending stress on the gear tooth. The transverse pressure angle $\phi_{t}$ is different from normal pressure angle $\phi_{n}$ due to the angularity of the helical gear teeth.

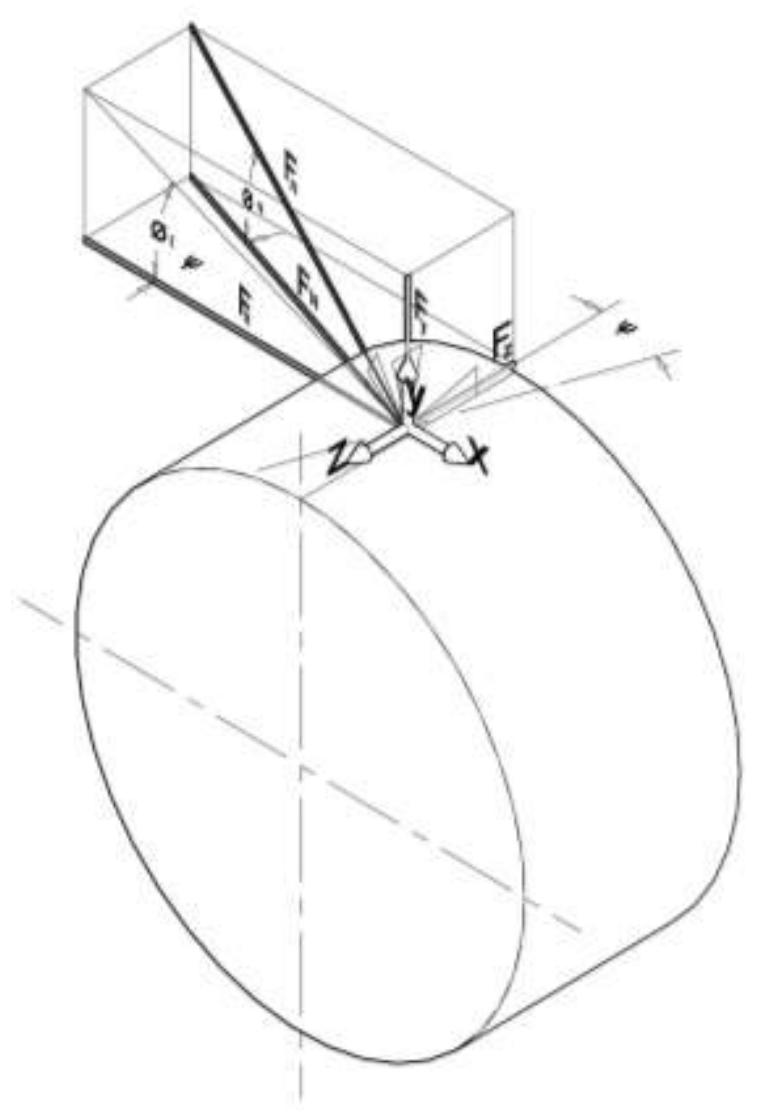

Fig. 1: Forces on helical gear tooth

The relationship between the pressure angles is [9]: 


$$
\tan \phi_{t}=\frac{\tan \phi_{n}}{\cos \psi}
$$

The following force relations may be verified by referring to standard books in machine design:

$$
\begin{aligned}
& T_{1}=\frac{30 P_{1} \times 10^{3}}{\pi N_{1}} \\
& F_{x}=\frac{T_{1} \times 10^{3}}{d_{1}} \\
& F_{y}=F_{x} \tan \phi_{t} \\
& F_{z}=F_{x} \tan \psi \\
& F_{N}=\frac{F_{x}}{\cos \psi} \\
& F_{n}=\frac{F_{x}}{\cos \psi \cos \phi_{n}}
\end{aligned}
$$

Though the driving force for a helical gearset is created in the transverse plane, actual contact of gear teeth occurs in the normal plane so the operation of a helical gearset depends on what happens on the normal plane. The normal plane intercepts the pitch cylinder so that the gear tooth profile generated in it has the same properties as the actual helical gear [6]. The normal plane therefore may be used to define an equivalent spur gear of a helical gear. The base helix angle according to Maitra [7] gives accurate estimate of the radius of curvature of the equivalent spur gear on the normal plane of contact. So the spur gear equivalent pitch diameter is:

$$
d_{n}=\frac{z m_{n}}{\cos ^{2} \psi_{b}}
$$

Where [20]:

$$
\tan \psi_{b}=\frac{\tan \psi}{\sqrt{1+\tan ^{2} \phi_{t}}}
$$

The pitch diameter of a helical gear is:

$$
d=\frac{z m_{n}}{\cos \psi}
$$

The contact ratio of the equivalent spur gearset is approximated [20] as:

$$
\begin{gathered}
\varpi_{n}=\frac{\varpi_{t}}{\cos ^{2} \psi_{b}} \\
\varpi_{t}=\frac{k_{1}+k_{2}}{\pi \cos \phi_{n}}
\end{gathered}
$$

And

$$
\begin{aligned}
& k_{1}=0.5\left(\sqrt{\left(z_{1}+2\right)^{2}-\left(z_{1} \cos \phi_{n}\right)^{2}}-z_{1} \sin \phi_{n}\right) \\
& k_{2}=0.5\left(\sqrt{\left(z_{2}+2\right)^{2}-\left(z_{2} \cos \phi_{n}\right)^{2}}-z_{2} \sin \phi_{n}\right)
\end{aligned}
$$

The transverse contact ratio $\varpi_{t}$ is for a fictitious spur gear and not the physical helical gear. It depends on the actual number of gear teeth on the physical helical gearset. The fictitious spur gearset is assumed to have the same number of teeth as the helical gearset and a transverse module equal to normal module of the helical gear. However the transverse contact ratio of the physical helical gear is not directly implied and is not equal to $\varpi_{t}$.

\subsection{Bending Fatigue Stress Capacity Model}

The forces $F_{x}$ and $F_{z}$ in Fig. 1 produce both bending and direct shear stresses at the root of the gear. The bending stress from the axial force causes axial stress variation from heel to toe of the gear tooth. The bending stresses are usually significantly larger than the shear stresses at low helix angles. As the helix angle increases, the force $F_{z}$ also increases so that the bending and direct shear stresses from it may become comparable to those from $F_{x}$. The force $F_{y}$ induces direct compressive stress at the root of the gear and is generally accounted for through the AGMA bending stress factor.

In a helical, the normal bending force $F_{N}$, acts perpendicular to the tooth similar to the transverse force in a spur gear. The analogous bending stress from this force may be expressed using normal plane parameters as:

$$
\sigma_{N}=\frac{F_{N}}{b_{n} m_{n} \varpi_{n} Y_{n}}
$$

$$
b_{n}=\frac{b}{\cos \psi}
$$

Substitute Eqs. (4a), (8a), and (11) in Eq. (12):

$$
\sigma_{N}=\frac{F_{x} \cos ^{2} \psi_{b}}{b m_{n} \varpi_{t} Y_{n}}
$$

The bending stress of Eq. (12) neglects the bending stress from the axial force and also the shear stresses from the 
transverse and axial forces in the helical gear. To account for these stresses, we will consider the equivalent spur gear of a helical gear to be loaded by transverse and axial forces but please note that actual spur gears do not experience axial loads. So consider Fig. 2 where an equivalent spur gear tooth

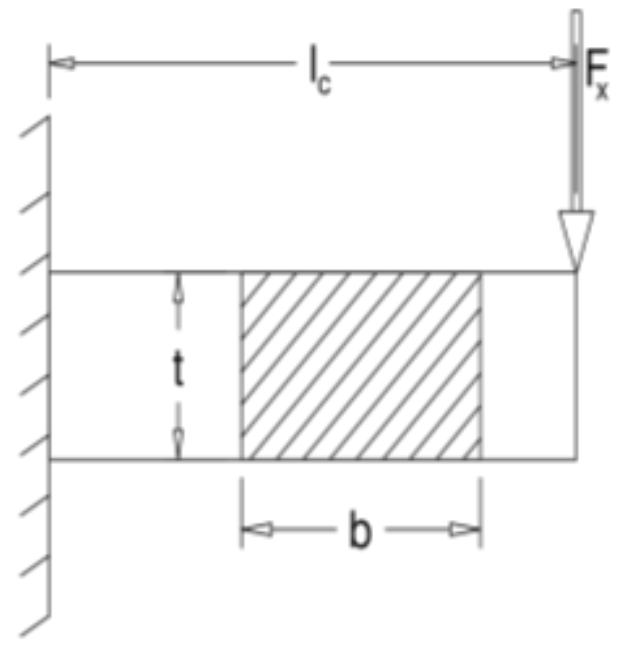

a) Transverse loading of a helical gear is modelled as a cantilever beam loaded in two planes. Fig. 2a is representative of the transverse loading while Fig. $2 b$ is representative of the axial loading. The bending and direct shear stresses from these loads will now be considered.

Fig. 2: Cantilever models of gear tooth in bending

\section{Bending Stresses}

The bending stress from the transverse load is:

$$
\begin{aligned}
& \sigma_{b x}=\frac{F_{x} l_{c}}{\mathrm{Z}_{\mathrm{t}}}=\frac{F_{x}}{\left(\mathrm{Z}_{\mathrm{t}} / l_{c}\right)} \\
& Z_{t}=\frac{b t^{2}}{6}
\end{aligned}
$$

However, based on AGMA standard:

$$
\sigma_{b x}=\frac{F_{x}}{b m_{t} J}
$$

Eq. (15) is the AGMA model for bending stress capacity model of a spur gear which is loaded in bending only by the transverse load. The equivalent spur gear we have in mind is loaded in bending by both transverse and axial forces. So the bending stress from the axial load is:

$$
\begin{aligned}
& \sigma_{b z}=\frac{F_{z} l_{c}}{\mathrm{Z}_{\mathrm{a}}}=\frac{F_{x} \tan \psi}{\left(\mathrm{Z}_{\mathrm{a}} / l_{c}\right)} \\
& Z_{a}=\frac{t b^{2}}{6}=\left(\frac{b}{t}\right) \frac{b t^{2}}{6}=\frac{b}{t} Z_{t}
\end{aligned}
$$

Substituting Eq. (17) in Eq. (16), we have:

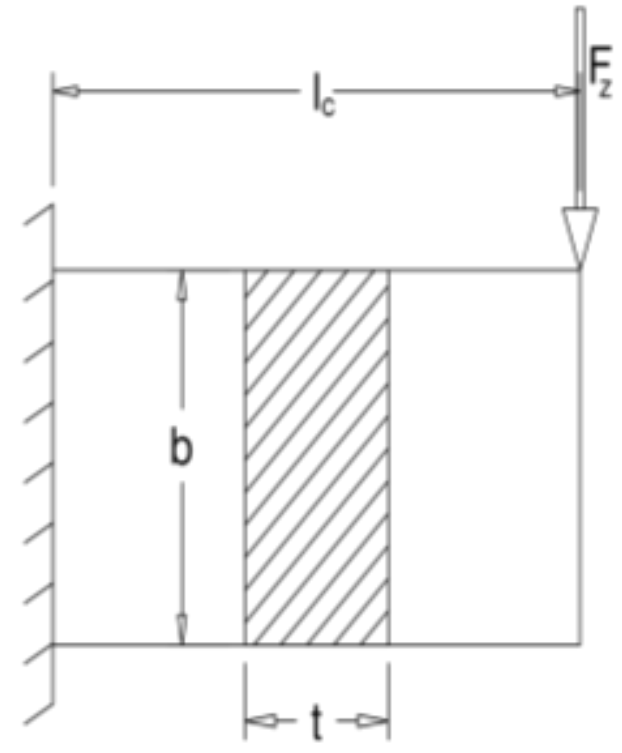

b) Axial loading

$$
\sigma_{b z}=\frac{F_{x} \tan \psi}{b m_{t} J}\left[\frac{t}{b}\right]=\sigma_{b x}\left[\frac{t}{b}\right] \tan \psi
$$

For a rectangular cross-section, the resultant bending stress at one of the corners is:

$$
\sigma_{b}=\sigma_{b x}+\sigma_{b z}=\frac{F_{x}}{b m_{t} J}\left(1+\frac{t}{b} \tan \psi\right)
$$

\section{Direct Shear Stresses}

The transverse and axial forces also induce direct shear stresses on the equivalent spur gear. The direct shear stress induced by the transverse load is:

$$
\tau_{s x}=\frac{F_{x} k_{\tau}}{b t}
$$

The stress concentration factor included in Eq. (20) is due to the geometric discontinuity caused by the root fillet. The direct shear stress from the axial load is:

$$
\tau_{s z}=\frac{F_{z}}{b t}=\frac{F_{x} k_{\tau}}{b t} \tan \psi
$$

The resultant shear stress is: 


$$
\tau_{s}=\sqrt{\tau_{s x}^{2}+\tau_{s z}^{2}}=\frac{F_{x} k_{\tau}}{b t} \sqrt{1+\tan ^{2} \psi}
$$

\section{Equivalent Root Tensile Stress}

Equivalent tensile stress may be based on distortion energy theory or maximum shear stress theory depending on whether the material is ductile or brittle [2, 11]. Most gears are made from ductile materials, so the equivalent tensile stress at the tooth root may be estimated by applying the distortion energy theory. For a plane stress situation, the equivalent tensile stress is:

$$
\sigma_{t}=\sqrt{\sigma_{b}^{2}+3 \tau_{s}^{2}}
$$

Substituting Eq. (19) and Eq. (22) into Eq. (23a), we have:

$$
\sigma_{t}=\frac{F_{x}}{b m_{t} J} \sqrt{\left(1+\frac{t}{b} \tan \psi\right)^{2}+3\left[\frac{J m_{t} k_{\tau}}{t}\right]^{2}\left(1+\tan ^{2} \psi\right)}
$$

We need an estimate of the gear tooth thickness at its root in Eq. (23b). Now we know for spur gears from Eqs. (13) to (15) that:

$$
\sigma_{b x}=\frac{F_{x}}{b} \frac{6 l_{c}}{t^{2}}=\frac{F_{x}}{b} \frac{1}{m_{t} J}
$$

Therefore:

$$
t=\sqrt{6 J m_{t} l_{c}}
$$

For properly designed low-contact ratio spur gearset, the transverse contact ratio is such that two pairs of teeth are in contact at the beginning and the end of the contact period in the transverse plane. Towards the middle of the contact period, a transition from two pairs to one pair of teeth in contact occurs. A similar transition from one pair to two pairs of teeth in contact occurs beyond the middle period of contact. The worst-load condition occurs when a single pair of teeth carries the full load transmitted at the transition of one pair to two pairs of teeth. This point corresponding to the worst-load condition is called the highest point of single tooth contact (HPSTC). Assuming the first point of contact coincides exactly with the dedendum point of the involute profile, the HPSTC will happen when the first point of contact in the transverse plane has moved just one base pitch up the line of action [10]. The line of action of a spur gear in a mesh may be construed as an incline plane with the angle of inclination being the transverse pressure angle as shown in Fig. 3. It is important to note that the tangential force is not constant along the inclined plane but attains a maximum value in the vicinity of the HPSTC [21]. At that point the lever arm of the force about the root point is $l_{c}$ as indicated in Fig. 6.

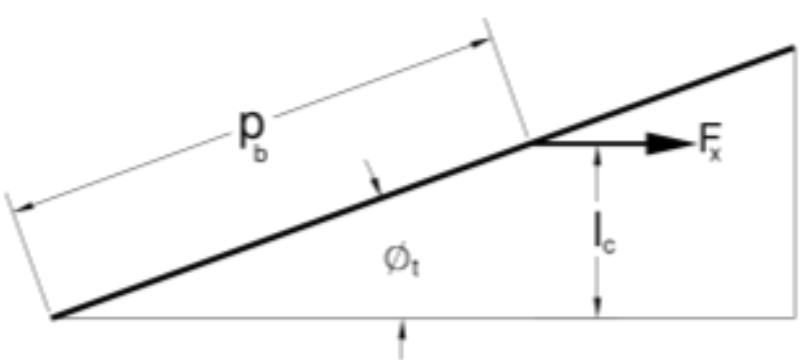

Fig. 3: Inclined plane model of tooth loading

From Fig. 6:

$$
l_{c} \approx p_{b} \sin \phi_{t}
$$

And:

$$
p_{b}=p_{t} \cos \phi_{t}=\pi m_{t} \cos \phi_{t}
$$

Hence:

$$
l_{c} \approx 0.5 \pi m_{t} \sin 2 \phi_{t}
$$

How reasonable is Eq. (25c)? For a spur gear when $\phi_{t}=20^{0}$, then $l_{c} \approx 1.01 m_{t}$. This means the worst load point is in the vicinity of the pitch circle diameter since the pitch circle diameter is one module above the dedendum circle diameter. This is not an unreasonable estimate since the HPSTC is known to be on the upper side of the pitch circle diameter [21] and pitting generally appears first at or below the pitch point on the pinion tooth $[2,7]$. Substituting (25c) into Eq. (24b), then:

$$
\begin{aligned}
& t=m_{t} \sqrt{3 \pi J \sin 2 \phi_{t}}=m_{t} \kappa \\
& \kappa=\sqrt{3 \pi J \sin 2 \phi_{t}}
\end{aligned}
$$

Substituting for $t$ in Eq. (23), the equivalent tensile stress for the equivalent spur gear is:

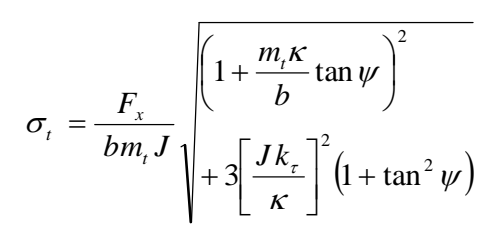

The above equation can be applied to a helical gear by inspection when we combine Eqs. (12) and (27), so that the estimate of the bending stress for a helical gear is obtained as:

$$
\sigma_{t}=\frac{F_{x} K_{t} \cos ^{2} \psi_{b}}{m_{n} b \varpi_{t} J_{n}}
$$


where:

$$
K_{t}=\sqrt{\left(1+\frac{m_{n} \kappa}{b} \frac{\tan \psi}{\cos \psi}\right)^{2}+3\left[\frac{J_{n} k_{\tau}}{\kappa}\right]^{2}\left(1+\tan ^{2} \psi\right)}
$$

$K_{t}$ is a stress modification factor that accounts for direct shear stresses from axial and transverse loads and also for the bending stress from the axial load. Even for spur gears, where $\psi$ is zero, Eq. (29) reduces to:

$$
K_{t}=\sqrt{1+3\left[\frac{J k_{\tau}}{\kappa}\right]^{2}}
$$

Eq. (30) suggests that $K_{t}$ is greater than unity even for spur gears.

The shear stress concentration factor $k_{\tau}$ (Eq. (29), Eq. (30)) is in general a function of material and geometry like the normal stress concentration factor in AGMA standards. The effective shear stress concentration is taken as 1.7 to 2.2 for flexible spline teeth generated with pinion cutter and 1.6 to 2.0 when the teeth are hobbed [22]. Flexible spline teeth are similar to those of cylindrical gears and are produced in similar ways, therefore, we will assume $k_{\tau}$ to be 2 in our model to be conservative.

Now:

$$
F_{x}=\frac{2 T_{1} \times 10^{3}}{d_{1}}=\frac{2 T_{2} \times 10^{3}}{d_{2}}
$$

The bending stress in helical gears is then estimated as:

$$
\sigma_{t}=\frac{2 K_{t} T \cos ^{2} \psi_{b} \times 10^{3}}{d b_{2} m_{n} \varpi_{t} J_{n}}
$$

Eq. (32) is the theoretical bending stress capacity of a helical gear based on its spur gear equivalency. Two issues need be addressed to convert it to a practical or engineering model. These are load shearing during transmission and the actual transmitted load. Load shearing is expected in helical gearsets but as in normal contact spur gears, load shearing will not be exactly equal to the transverse contact ratio. Similarly the load shearing in the equivalent spur gear model will not be exactly equal to $\varpi_{t}$. Therefore, we shall substitute $\varpi_{s}$ for $\varpi_{t}$ as load shearing factor in the above formula.

The actual transmitted load is known from experience to be greater than the rated transmitted load. This is because manufacturing tolerances, elastic deformation of machine elements and supporting structures, local accelerations and decelerations of gear drives, external dynamics of devices coupled with gear drives, foundation vibrations, etc. induce vibrations on meshing gears that magnify the rated transmitted load. Therefore, to account for the load increases on the rated transmitted load in practice, a service load factor $K_{s}$ will be introduced into the theoretical model. Consequently the engineering bending stress capacity model of a helical gear is:

$$
\begin{aligned}
& \sigma_{F}=\frac{2 K_{s} K_{t} T \cos ^{2} \psi_{b} \times 10^{3}}{d b m_{n} \varpi_{s} Y_{n}} \leq S_{b} \\
& S_{b}=\frac{S_{F}}{n_{F}} \\
& Y_{n}=f\left(z_{n}\right)
\end{aligned}
$$

The equivalent spur gear teeth

$$
z_{n}=\frac{z}{\cos ^{2} \psi_{b} \cos \psi} \approx \frac{z}{\cos ^{3} \psi_{b}}
$$

The parameter $Y_{n}$ in Eq. (33a) is used as an approximation of the AGMA $J_{n}$-factor and can be estimated as [23]:

$$
Y_{n}=0.875 J_{n}^{\prime} \varpi_{t}
$$

AGMA $J_{n}^{\prime}$ values for standard full-depth involute $20^{\circ}$ normal pressure angle gears may be obtained as [23].

For $12 \leq \mathrm{z}<70$

$$
\begin{aligned}
J_{n}^{\prime}= & -9 z_{n}^{4} \times 10^{-9}+2.45 z_{n}^{3} \times 10^{-6} \\
& -2.25 z_{n}^{2} \times 10^{-4}+9.15 z_{n} \times 10^{-3}+0.1308
\end{aligned}
$$

For $70 \leq \mathrm{z}<300$

$J_{n}^{\prime}=-3 z_{n}^{2} \times 10^{-8}+9 z_{n} \times 10^{-5}+0.285$

\section{DESIGN SIZING BASED ON BENDING FATIGUE}

The objective in design sizing is to obtain initial estimate of a component size based on specific serviceability criteria. For bending fatigue failures, the bending fatigue strength is the limit of capacity and failures are often sudden. Now, gear design is an iterative process and the initial solution provides trial values of gear sizes. The basic gear size 
parameter is the module, therefore finding an initial module value is the primary goal of gear design sizing.

Now:

$$
\begin{aligned}
& d_{1}=\frac{z_{1} m_{n}}{\cos \psi} \\
& b=\lambda_{b} d_{1}=\frac{\lambda_{b} z_{1} m_{n}}{\cos \psi}
\end{aligned}
$$

Substitute Eq. (36) into Eq. (33a) and obtain:

$$
\sigma_{F}=\frac{2 K_{s}^{\prime} K_{t}^{\prime} T_{1} \times 10^{3} \cos ^{2} \psi_{b} \cos ^{2} \psi}{\lambda_{b} z_{1}^{2} m_{n}^{3} \varpi_{s} Y_{n}}
$$

where:

$$
K_{t}^{\prime}=\sqrt{\left(1+\frac{\kappa}{\lambda_{b} z_{1}} \tan \psi\right)^{2}+3\left[\frac{J_{n} k_{\tau}}{\kappa}\right]^{2}\left(1+\tan ^{2} \psi\right)}
$$

Eq. (38) is obtained by substituting Eq. (36b) into Eq. (29) and it is the initial estimate of $K_{t}$. A conservative version of Eq. (37) is obtained when $\psi$ is set equal to $\psi_{b}$. Hence for sizing purposes:

$$
\sigma_{F}=\frac{2 K_{s}^{\prime} K_{t}^{\prime} T_{1} \times 10^{3} \cos ^{4} \psi_{b}}{\lambda_{b} z_{1}^{2} m_{n}^{3} \varpi_{s} Y_{n}} \leq S_{b}
$$

From Eq. (39):

$$
m_{n} \geq 10 \cos \psi_{b}\left[\frac{2 K_{s}^{\prime} K_{t}^{/} T_{1} \cos \psi_{b}}{\lambda_{b} z_{1}^{2} \varpi_{s} Y_{n} S_{b}}\right]^{1 / 3}
$$

Now, the service factor $K_{s}$ is generally a function of the pitch velocity and gear sizes through the component parameters $K_{v}, K_{m}$ and $K_{r}$. Since gear sizes are not kwon at the beginning of the design process, we need an initial estimate of $K_{s}$. The external overload factor $K_{o}$ can be selected based on the drive characteristics of the power source and driven devices. An initial approximate value of $K_{m}$ based on [11] but slightly modified for helical gears is:

$$
K_{m}^{\prime} \approx 1+0.93 \lambda_{b}\left[0.20+0.0112\left(\frac{2 K_{o} T_{1}}{\lambda_{b}}\right)^{1 / 3}\right]
$$

Eq. (41a) clearly shows the dependence of $K_{m}$ on the rated load and so is $K_{v}$ because it depends on the pitch point speed and gear tooth quality number. The gear tooth quality number is often selected based on the tangential velocity which is determined by the gear pitch diameter and its rotational speed. It is thus suggested that its initial value may be estimated as:

$$
K_{v}^{\prime} \approx 2 K_{m}-1
$$

Then the service load factor for design sizing may be estimated as:

$$
K_{s}^{\prime} \approx K_{o} K_{v}^{\prime} K_{m}^{\prime}
$$

The estimate of the gear module becomes:

$$
m_{n} \geq 10 \cos \psi_{b}\left[\frac{2 K_{s}^{\prime} K_{t}^{\prime} T_{1} \cos \psi_{b}}{\lambda_{b} z_{1}^{2} \varpi_{s} S_{t}}\right]^{1 / 3}
$$

where:

$$
S_{t}=\min \left(Y_{n 1} S_{b 1}, Y_{n 2} S_{b 2}\right)
$$

To avoid interference, the smallest helical pinion teeth number that can run with a rack must be maintained [4] Now, gear ratio in single-helix gearsets can be up to 10 and may be up to 15 in double-helix gearsets. For speedreducing drive with $\mu_{o} \leq 15$, it is suggested that:

$$
z_{1}=\max \left(\frac{2 \cos \psi}{\sin ^{2} \phi_{t}}, 26-1.25 \mu_{o}\right)
$$

In the Appendix, it is shown that the base circle diameter of a spur gear is smaller than the dedendum circle diameter if the number of gear teeth is more than 33. Thus for high speed gearing, a minimum pinion teeth number of 33 is suggested for spur gears so that the working depth is completely of involute profile. For helical gears, the suggested minimum for high speed applications is $33 \cos ^{3} \psi_{b}$. This will maximize the transverse contact ratio and therefore enhance load sharing and reduce gear noise.

A tentative maximum value of $\lambda_{b}$ for medium-hard gears may be obtained as:

$$
\lambda_{b} \approx 0.275+\frac{0.8 \mu_{o}}{\mu_{o}+1}
$$

Eqs. (43) and (44) allows us to provide initial values of these parameters in Eq. (42a) in order to estimate the normal module. Thereafter, a standard normal module value is chosen and the helical gearset basic dimensions are determined. The number of gear teeth is estimated as: 


$$
z_{2} \approx \mu_{o} z_{1}
$$

An integer value for $z_{2}$ must be chosen. Then refine:

$$
\mu=\frac{z_{2}}{z_{1}}
$$

Choosing a higher module value than estimated allows a designer to reduce $z_{1}$ and $z_{2}$ while keeping $\mu$ constant. When a hunting tooth is used in power drives, the speed ratio error or tolerance should be checked. That is:

$$
\epsilon_{o}=100\left[\frac{\mu_{o}-\mu}{\mu_{o}}\right]
$$

When a satisfactory value of $\epsilon_{o}$ is obtained, then:

$$
\begin{aligned}
& d_{1}=\frac{m_{n} z_{1}}{\cos \psi} \\
& d_{2}=\frac{m_{n} z_{2}}{\cos \psi} \\
& C=\frac{d_{1}+d_{2}}{2}=\frac{m_{n}\left(z_{1}+z_{2}\right)}{2 \cos \psi} \\
& b_{2}=\lambda_{b} d_{1} \\
& \varpi_{f}=\frac{b_{2} \sin \psi}{\pi m_{n}} \geq 1.15 \\
& b_{1} \leq b_{2}+5 \mathrm{~mm}
\end{aligned}
$$

\section{Model Applications}

The new design bending stress capacity model presented in the previous section is tested in five design examples which involve design verification tasks and one example of design sizing and verification tasks. The relevant equations were coded in Microsoft Excel for computational efficiency. The spreadsheet has two pages and the first page has a material selection and strengths estimation sections. The second page has design sizing and design verification sections. Iteration during design verification can be done by changing the value of effective face width, gear module, and gear teeth. The gear pitch diameter is changed when either the module or gear teeth number is changed.

\section{Design Example Problems}

Example 1: A 17-tooth helical steel pinion with a right-hand helix angle of $30^{\circ}$ rotates at $1800 \mathrm{rpm}$ when transmitting 3
$\mathrm{kW}$ to a 52-tooth helical steel gear. The gearset has a normal pressure angle of $20^{\circ}$, normal module of $2.54 \mathrm{~mm}$, and a face width of $38.1 \mathrm{~mm}$. Determine the bending stress on the pinion for a service load factor of 1.769 [4, p. 771 - 773].

Example 2: A 15-tooth helical steel pinion with a right-hand helix angle of $41.41^{\circ}$ rotates at $2500 \mathrm{rpm}$ when transmitting $3.75 \mathrm{~kW}$ to a 24-tooth helical steel gear. The gearset has a normal pressure angle of $20^{\circ}$, normal module of $2.54 \mathrm{~mm}$, and a face width of $29.21 \mathrm{~mm}$. Determine the bending stress on the pinion for a service load factor of 1.84 [2, p. $658-$ 662].

Example 3: A helical steel gearset for a milling machine drive is to transmit $48.5 \mathrm{~kW}$ from an electric motor with a pinion speed of $3450 \mathrm{rpm}$ and a gear speed of $1100 \mathrm{rpm}$. The gearset has a normal pressure angle of $20^{\circ}$ and a helix angle of $15^{\circ}$. The pinion has 24 teeth, gear has 75 teeth, the normal module is $2.17 \mathrm{~mm}$ and the face with is $58.15 \mathrm{~mm}$. Determine the bending stress on the pinion for a service load factor of 2.552 [19, p. 461 - 462].

Examples 4 \& 5: A 3-helical steel gear train transmits 15 $\mathrm{kW}$ at $2500 \mathrm{rpm}$ at the pinion. The pinion has 14 teeth, idler has 17 teeth and the gear has 49 teeth. The gearset has a normal pressure angle of $25^{\circ}$, helix angle of $20^{\circ}$, normal module of $4.233 \mathrm{~mm}$, and face width of $67.74 \mathrm{~mm}$. Determine the bending stresses on the pinions for a service load factor of 2.424 [24, p. 764 - 768]. Note that two gearsets are involved in this problem: pinion-idler (Example 4), and idler-gear (Example 5) combinations.

\section{Solutions: Examples 1 to 5}

Table 1 summarizes the basic gearset dimensions and load data for examples 1 to 5 . The service load factor value for each example is made identical to the values in the references so that the numerical bending stress values for each example can be properly compared with previous results. Table 2 shows the AGMA bending stress values in column 3 and the new model bending stress values in column 4. The percentage difference between the new bending stress capacity model values and AGMA values are indicated in column 5 . The variances between the results are in the range of $-7 \%$ to $10 \%$ in the wide range of helix angles which span $15^{\circ}$ to $41.41^{\circ}$. Clearly the new model appears to compare favorably with AGMA model results. According to Matthew [25], simplified engineering models can yield $\pm 10 \%$ accuracy. From the favorable comparison of the five examples presented with AGMA model, it seems reasonable to accept the new model for preliminary design which is tested in Example 6. 
Table 1: Input Parameters for Bending stress for Examples

\begin{tabular}{|l|l|l|l|l|l|}
\hline \multirow{2}{*}{ Parameters } & Examples & \multicolumn{4}{l|}{} \\
\cline { 2 - 6 } & 1 & 2 & 3 & 4 & 5 \\
\hline Transmitted power $(\mathrm{kW})$ & 3 & 3.75 & 48.5 & 15 & 15 \\
\hline Pinion speed (rpm) & 1800 & 2500 & 2450 & 2500 & 2056 \\
\hline Pinion torque (Nm) & 15.92 & 14.32 & 134.24 & 57.30 & 69.67 \\
\hline Speed ratio & 3.0 & 1.60 & 3.136 & 1.216 & 2.884 \\
\hline Normal pressure angle $\left(^{\circ}\right)$ & 20 & 20 & 20 & 25 & 25 \\
\hline Helix angle $\left(^{\circ}\right)$ & 30 & 41.41 & 15 & 20 & 20 \\
\hline Normal module $(\mathrm{mm})$ & 2.54 & 2.54 & 2.17 & 4.233 & 4.233 \\
\hline Pinion teeth number & 17 & 15 & 24 & 14 & 17 \\
\hline Gear teeth number & 51 & 24 & 75 & 17 & 49 \\
\hline Pinion pitch diameter $(\mathrm{mm})$ & 49.86 & 50.8 & 53.92 & 63.07 & 76.58 \\
\hline Gear pitch diameter $(\mathrm{mm})$ & 149.58 & 81.28 & 168.49 & 76.58 & 220.73 \\
\hline Face width (mm) & 38.1 & 24.13 & 57.15 & 67.74 & 67.74 \\
\hline Service load factor & 1.769 & 1.840 & 2.472 & 2.424 & 2.424 \\
\hline
\end{tabular}

Table 2: Bending Stress Solutions for Example 1 to 5

\begin{tabular}{|l|l|l|l|l|}
\hline \multirow{2}{*}{ Source } & Face Contact & Pinion Bending Stress (MPa) & \multirow{2}{*}{ Difference (\%) } \\
\cline { 3 - 4 } & Ratio & AGMA & New & \\
\hline Budynas [4] & 2.39 & 27.60 & 26.16 & 5.22 \\
\hline Collins [ 2] & 2.00 & 40.02 & 36.16 & 9.65 \\
\hline Mott [19] & 2.17 & 242.24 & 250.93 & -3.59 \\
\hline Norton [24] & 1.74 & 31.85 & 36.58 & -0.74 \\
\hline Norton [24 ] & 1.74 & 30.10 & 34.00 & -6.52 \\
\hline
\end{tabular}

Table 3: Shear Stress Contributions in Example 1 to 5

\begin{tabular}{|c|c|c|c|c|}
\hline \multirow{2}{*}{ Source } & \multirow{2}{*}{$\begin{array}{l}\text { Helix } \\
\text { (deg.) }\end{array}$} & \multicolumn{2}{|c|}{ Stress Modification Factor } & \multirow{2}{*}{$\begin{array}{l}\text { Shear Stress } \\
\text { Contribution }(\%)\end{array}$} \\
\hline & & Bending & Total & \\
\hline Budynas [4] & 30 & 1.071 & 1.429 & 25.05 \\
\hline Collins [2] & 41.41 & 1.011 & 1.570 & 35.61 \\
\hline Mott [19] & 15 & 1.016 & 1.351 & 24.80 \\
\hline Norton [24] & 20 & 1.044 & 1.375 & 24.07 \\
\hline Norton [ 24] & 20 & 1.045 & 1.389 & 24.77 \\
\hline
\end{tabular}

\section{Shear Stress Contributions}

Eq. (29) and Eq. (33a) show that the shear stresses contribute to the equivalent root bending stress. It is logical then to estimate the degree of contribution in the examples considered above. This is summarized in Table 3 from which, we note that the contribution of the shear stresses is significant in each example, being more that $20 \%$. Also, the contribution is greater for higher helix angles as expected since the axial load increases with increasing helix angle.

Example 6: Design a pair of helical steel gears is to transmit $8.5 \mathrm{~kW}$ from an electric motor with the pinion running at $720 \mathrm{rpm}$ and the gear at $144 \mathrm{rpm}$. The normal pressure angle is $20^{\circ}$ while the helix angle is $20^{\circ}$. The gears are made from carbon steel material and are each thru-hardened to 300 HVN. Design the gearset for a minimum life of $10^{8}$ load cycles based on $99 \%$ reliability. Assume an external overload factor of 1.5.

Solution 6: A minimum life of $10^{8}$ load cycles implies the slower running gear should last at least $10^{8}$ load cycles. This information was used to determine the design bending strength of the gearset, indicating that the pinion is weaker, with an estimated design bending fatigue strength of 219 $\mathrm{MPa}$. Gear design bending fatigue strength was determined on the basis of AGMA recommendations. AGMA gear material nominal strength data are determined at $99 \%$ reliability at $10^{7}$ load cycles. Nominal strengths are usually determined experimentally in controlled environments. For field applications, the nominal strengths need adjustments, so AGMA [26] recommends several factors as modifiers. Please refer to the Appendix for a very brief discussion.

Table 4: Design Sizing for Example 6

\begin{tabular}{|l|l|}
\hline Parameter & Value \\
\hline Transmitted power $(\mathrm{kW})$ & 8.5 \\
\hline Pinion rotational speed (rpm) & 720 \\
\hline Pinion rotational speed (rpm) & 144 \\
\hline Desired speed ratio & 5 \\
\hline Pinion number of teeth & 19 \\
\hline External overload factor & 1.50 \\
\hline Composite elastic modulus $(\mathrm{GPa})$ & 230 \\
\hline Pinion torque (Nm) & 112.73 \\
\hline Core hardness (HVN) & 300 \\
\hline
\end{tabular}




\begin{tabular}{|l|l|}
\hline Design bending fatigue strength (MPa) & 219 \\
\hline Desired design factor & 1.25 \\
\hline Service load factor & 2.72 \\
\hline Normal module $(\mathrm{mm})$ : estimate & 2.78 \\
\hline Normal module $(\mathrm{mm})$ : chosen & 3.0 \\
\hline
\end{tabular}

Table 4 shows other design sizing parameters. Design sizing estimates yielded pinion teeth number of 19 , gear teeth number of 95 , and normal module value $2.78 \mathrm{~mm}$ based on bending fatigue resistance. A standard normal module value of $3 \mathrm{~mm}$ [19] was chosen. Table 5 shows the design verification data for the first iteration which yielded acceptable results because a design factor of 1.74 is obtained against a desired value of 1.25 . The service load factor estimate for design sizing is 2.72 based on a shape factor of 0.90 . The corresponding value for design verification based on a shape factor of 0.99 is 2.48 .

Table 5: Design Verification for Example 6

\begin{tabular}{|l|l|}
\hline Parameter & Value \\
\hline Normal pressure angle $\left({ }^{\circ}\right)$ & 20 \\
\hline Helix angle $\left({ }^{\circ}\right)$ & 20 \\
\hline Normal module $(\mathrm{mm})$ & 3.0 \\
\hline Pinion teeth & 19 \\
\hline Gear teeth & 95 \\
\hline Design speed ratio & 5 \\
\hline Pinion pitch diameter $(\mathrm{mm})$ & 60.66 \\
\hline Gear pitch diameter $(\mathrm{mm})$ & 303.29 \\
\hline Pinion face width $(\mathrm{mm})$ & 60 \\
\hline Face contact ratio & 2.18 \\
\hline Service load factor & 2.48 \\
\hline Root bending stress $(\mathrm{MPa})$ & 126.0 \\
\hline Estimated design factor for pinion & 1.74 \\
\hline &
\end{tabular}

\section{CONCLUSION}

A bending fatigue stress capacity model of helical gears is presented. The model gives estimate of the bending stress expected at the tooth root in a helical gear. Several design examples of root bending stresses from different references are computed and they compare very favorably with AGMA estimates because the percentage variances between the two model values are in the range of -7 to $10 \%$ in the examples. It is important to note the wide range of the helix angle which spans $15^{\circ}$ to $41.41^{\circ}$ and the different normal pressure angles of $20^{\circ}$ and $25^{\circ}$ in the examples considered. Secondly, the new model appears to give slightly higher bending stress values in general so that for preliminary design, it offers the advantage of providing conservative solutions. The favorable comparison should give some confidence in using the new model for preliminary design tasks of helical gears. In the Examples 1 to 5 considered, the shear stress contribution to the total root bending stress varies from about $24 \%$ to $36 \%$. This is quite significant, so that ignoring it may result in early failure of helical gears.
The new bending stress capacity model was modified for design sizing and its application is demonstrated in example 6. Design sizing provides the value of gear normal module based on bending fatigue which is used to determine the other basic dimensions of a gearset.

For high speed gearing, a minimum pinion teeth number of 33 is suggested for spur gears so that the working depth is completely of involute profile. For helical gears, the suggested minimum for high speed applications is $33 \cos ^{3} \psi_{b}$.

The very favorable comparison obtained between the new bending stress capacity model and AGMA values allows us to conclude that the bending stress capacity model presented is sufficiently accurate enough to be acceptable for preliminary design of helical gears. This model may be used for spur design if the helix angle is taken as $0^{\circ}$.

\section{ACKNOWLEDGEMENT}

The authors gratefully acknowledge that this study was supported in parts with funds from COSET Research Fund and the University Faculty Development Fund of Texas Southern University, Houston, Texas.

\section{NOMENCLATURE}

HVN = Hardness: Vicker's Number

HPSTC $=$ Highest Point of Single Tooth Contact

$b=$ Effective gear face width (mm)

$b_{1}=$ Pinion face width $(\mathrm{mm})$

$b_{2}=$ Gear face width $(\mathrm{mm})$

$C=$ Center distance $(\mathrm{mm})$

$C_{o}=$ Operating center distance $(\mathrm{mm})$

$d_{1}=$ Pitch circle diameter of pinion $(\mathrm{mm})$

$d_{2}=$ Pitch circle diameter of gear $(\mathrm{mm})$

$F_{n}=$ Normal contact force $(\mathrm{N})$

$F_{N}=$ Normal bending force $(\mathrm{N})$

$F_{x}=$ Rated transmitted or transverse force $(\mathrm{N})$

$F_{y}=$ Rated radial force $(\mathrm{N})$

$F_{z}=$ Rated axial force $(\mathrm{N})$

$J=$ AGMA geometric stress factor at HPSTC

$J^{\prime}=$ AGMA J-factor for load at gear tooth tip

$k_{1}=$ Approach path factor

$k_{2}=$ Recess path factor

$K_{t}=$ Stress correction factor

$k_{\tau}=$ Shear stress concentration factor

$K_{s}=$ Service load factor

$K_{o}=$ External overload factor

$K_{v}=$ Internal overload factor 
$K_{m}=$ Mesh overload factor

$K_{r}=$ Rim rigidity factor

$K_{c}=$ Contact quality factor

$m_{t}=$ Transverse module of gear $(\mathrm{mm})$

$m_{n}=$ Normal module of gear $(\mathrm{mm})$

$m_{z}=$ Axial module of gear (mm)

$n_{F}=$ Design factor for bending fatigue strength

$N=$ Rotational speed (rpm)

$N_{1}=$ Rotational speed of pinion (rpm)

$N_{2}=$ Speed of gear (rpm)

$P_{1}=$ Power at pinion $(\mathrm{kW})$

$q_{n}=$ Gear tooth quality number

$T_{1}=$ Rated torque at pinion $(\mathrm{Nm})$

$T_{2}=$ Rated torque at gear $(\mathrm{Nm})$

$S_{b}=$ Allowable bending fatigue stress (MPa)

$S_{F}=$ Design bending fatigue strength (MPa)

$S_{F}^{\prime}=$ Nominal design bending fatigue strength (MPa)

$S_{u t}=$ Ultimate tensile strength (MPa)

$\sigma_{t}=$ Equivalent root bending stress $(\mathrm{MPa})$

$S_{t}=$ Factored bending fatigue strength $(\mathrm{MPa})$

$V_{t}=$ Tangential velocity at pitch point $(\mathrm{m} / \mathrm{s})$

$Y=$ Estimate of AGMA $\mathrm{J}$ factor at HPSTC

$Y_{b f}=$ Bending fatigue strength adjustment factor

$Y_{b b}=$ Bi-directional bending stress factor

$Y_{b i}=$ Induction/flame hardening root factor

$Y_{b n}=$ Bending fatigue durability factor

$Y_{b r}=$ Gear reliability factor for bending

$Y_{b z}=$ Bending fatigue size factor

$z=$ Number of teeth on pinion or gear

$\phi_{t}=$ Transverse pressure angle (deg.)

$\phi_{n}=$ Normal pressure angle (deg.)

$\psi=$ Helix angle (deg.)

$\psi_{b}=$ Base helix angle (deg.)

$\mu=$ Design speed ratio

$\mu_{o}=$ Desired speed ratio

$\varpi_{t}=$ Transverse plane contact ratio

$\varpi_{f}=$ Face contact ratio

$\sigma_{b}=$ Maximum gear root bending stress $(\mathrm{MPa})$

$\sigma_{H}=$ Maximum Hertz bending stress (MPa)

$\epsilon_{\psi}=$ Helix angle error $\epsilon_{o}=$ Speed ratio error

$\lambda_{b}=$ Gear aspect ratio or face width factor

$1=$ Subscript for pinion

$2=$ Subscript for gear

\section{REFERENCES}

[1] Spur Gear Design, http://www.learnengineering.org/2013/02/spur-geardesign.html

[2] Collins, J. A., Busby, H., Staab, G. H., (2010), Mechanical Design of Machine Elements and Machines: A Failure Prevention Perspective, $2^{\text {nd }}$ ed., John Wiley and Sons, New York.

[3] Khurmi, R. S. \& Gupta, J. K., A Textbook of Machine Design, Eurasia Publishing House, New Delhi.

[4] Budynas, R. G. \& Nissbett, J. K., Shigley's Mechanical Engineering Design, 9th ed., McGraw Hill Education.

[5] Partridge, J. R., High Speed Gears-Design and Applications: http://turbolab.tamu.edu/proc/turboproc/T6/T6pg133142.pdf

[6] Rortbart, H. A. \& Brown, T. H. (2006), Mechanical Design Handbook, $2^{\text {nd }}$ ed., McGraw-Hill, New York.

[7] Maitra, G. M., (2013), Fundamentals of Toothed Gearing: Handbook of Gear Design, $2^{\text {nd }}$ ed., McGraw Hill, New Delhi.

[8] Bhandari, V. B. (2010), Design of Machine Elements, $3^{\text {rd }}$ ed., McGraw Hill, India.

[9] Shigley, J. E and Mischke, C. R. (Chief Editors), (1996), Standard Handbook of Machine Design, McGraw-Hill, New York.

[10] Dudley, D. W. (2009), Handbook of Practical Gear Design, CRC Press, Baca Raton.

[11] Schmid, S. R., Hamrock, B. J. \& Jacobson,B. O., (2014), Fundamentals of Machine Elements, $3^{\text {rd }}$ ed., CRC Press, New York.

[12] Bergseth, E. (2009), Influence of Gear Surface Roughness, Lubricant Viscosity and Quality Level on ISO 6336 Calculation of Surface Durability, Technical Report, Department of Machine Design, Royal Institute of Technology, Stockholm, https://www.divaportal.org/smash/get/diva2:489751/FULLTEXT01.pd $\mathrm{f}$

[13] Bommisetty, V. S. N. K, (2012), Finite Element Analysis of Spur Gear Set, Masters' Thesis, Mechanical engineering Department, Cleveland State University.

[14] Peterson, R. E., (1974), Stress Concentration Factors, John Wiley, New York, pp. 270 - 271.

[15] ASM Metals Handbook, (1975), Failures of Gears, Failure Analysis and Prevention ( $\left.8^{\text {th }} \mathrm{ed},\right)$, Vol. 10, pp. $507-524$.

[16] Beckman, K. O., \& Patel, V. P. Review of API Versus AGMA Gear Standards-Rating, Data Sheet 
Completion, and Gear Selection Guidelines, pp. 191 $-204$

[17] Gidado, A. Y., Muhammad, I., \& Umar, A. A., (2014), Design, Modeling and Analysis of Helical Gear According to Bending Strength Using AGMA and ANSYS. Int'l Journal of Engineering Trends and Technology, Vol. 8, No 9.

[18] RoyMech, Helical Gears: http://www.roymech.co.uk/Useful_Tables/Drive/Heli cal_Gears.html

[19] Mott, R. L. (2004), Machine Elements in Mechanical Design, $4^{\text {th }}$ ed. SI, Pearson Prentice Hall, New York.

[20] Osakue, E. E. and Anetor, L., Contact Fatigue Design of Helical Gear By Spur Gear Equivalency, Int'l Journal of Research in Engineering and Technology, (In Print).

[21] Rameshkumar, M., Venkatesan, G. and Sivakumar, P. (2010), Finite Element Analysis of High Contact Ratio Gear, AGMA Technical Paper, https://www.agma.org/assets/uploads/publications/10 FTM06_Rameshkumar.pdf.

[22] Chernilevsky, D, A Practical Course in Machine Design, MIR, Moscow, p. 93.

[23] Osakue, E. E., (2016), Simplified Spur Gear Design, Proceedings of International Mechanical Engineering Congress and Exposition 2015, Paper Number IMECE2016-65426, November 11-17, Phoenix Arizona, USA.

[24] Norton, R. L. (2000), Machine Design: An Integrated Approach, Prentice-Hall, Upper Saddle River, New Jersey.

[25] Matthew, C. (2005), ASME Engineers Data Book, $2^{\text {nd }}$ ed., ASME Press, New York.

[26] AGMA 2001-D04, Fundamental Rating Factors and Calculation Methods for Involute Spur and Helical Gear Teeth: http://wp.kntu.ac.ir/asgari/AGMA\%202001-D04.pdf

[27] IS 210: Grey Iron Castings: Bureau of Indian Standards,

https://archive.org/details/gov.in.is.210.2009

\section{APPENDIX}

\section{Base Circle less than Dedendum Circle}

In gear generation process, the gear being produced and the cutter are in mesh like two gears rolling on their pitch cylinders [7]. For pinions with small number of teeth, interference can occur if the cutter extends beyond the base circle. The profile created at the section beyond the base circle deviates from true involute, preventing conjugate action in operation. Also, a recess is cut at the root of the gear tooth, weakening its bending resistance. The condition to ensure that the base circle diameter is smaller than the dedendum circle diameter is:

$$
2 r \cos \phi_{t} \leq 2\left(r-m_{t}\right)
$$

After simplification, Eq. (A1) reduces to:

$$
z \geq \frac{2}{1-\cos \phi_{t}}
$$

For a spur gear when $\phi_{t}=20^{\circ}$ :

$$
z \geq \frac{2}{1-\cos 20^{\circ}}=33.2
$$

Therefore, when $z>33$ in generated gears, the base circle diameter is smaller than the dedendum circle diameter. This means the working depth of the gear tooth will be completely of involute profile which will give the maximum contact ratio. Consequently, load shearing will be maximized and gear noise reduced.

For helical gears, the gear teeth number to ensure complete involute profile of the working depth is:

$$
z \geq 33.2 \cos ^{3} \psi_{b}
$$

To minimize noise and maximize load shearing in high speed gearing for generated gears, the pinion teeth number should be chosen as indicated in Eq. (A3) and Eq. (A4) for spur and helical gears, respectively for standard ISO gear proportions.

\section{Estimating Design Bending Fatigue Strength}

Contact fatigue strength is related to surface hardness while bending fatigue strength is related to core hardness [2, 3, 4, $6,7,8,9,11,19,22,24]$. Many of the AGMA available gear nominal strength data have been developed from tests of actual gear teeth so they better represent reality than general material strength data [4]. AGMA gear material nominal strength data are determined at $99 \%$ reliability at $10^{7}$ load cycles. Nominal strengths are usually determined experimentally in controlled environments. For field applications, the nominal strengths need adjustments, so AGMA [26] recommends several factors as modifiers.

For AGMA grade 1 thru-hardened steel, the nominal bending fatigue strength may be estimated [3] as:

$$
S_{F}^{\prime}=0.515 H_{s}+88
$$

The design strength is obtained as:

$$
\begin{aligned}
& S_{F}=Y_{b f} S_{F}^{\prime} \\
& Y_{b f}=Y_{b n} Y_{b r} Y_{b z} Y_{b i} Y_{b b}
\end{aligned}
$$

AGMA provides methods for evaluating most of the parameters in Eqs. (A6) and (A7). The allowable or design bending stress is: 


$$
S_{b}=\frac{S_{F}}{n_{F}}
$$

AGMA provides no specific recommendations for $n_{H}$. As a general guide, it is suggested $n_{F}=1.25$ for normalized steel, $n_{F}=1.35$ for quenched-tempered steel, and $n_{F}=1.55$ for case-hardened steel and cast iron.

\section{Cast Iron Gears}

Equivalent tensile stress may be based on maximum shear theory for brittle materials like cast iron $[2,11]$. In this case, the equivalent tensile stress at the tooth root may be estimated as:

$$
\sigma_{t}=\sqrt{\sigma_{b}^{2}+4 \tau_{s}^{2}}
$$

It should be noted that Eq. (29) may be used for gears of cast iron materials also, though they are generally considered to be brittle materials. This is because the parameter $3 k_{\tau}^{2}$ is the main determinant in such cases. Generally, notch sensitivity of cast iron materials is low. For instance, a maximum normal stress concentration factor of about 1.2 was estimated on available data in IS 210: 2009 [27] for gray cast iron. Assuming maximum shear stress theory of failure for brittle materials; $3 k_{\tau}^{2}$ becomes $4 k_{\tau}^{2}$. Now $4(1.2)^{2}$ or 5.76 is less than $3(2)^{2}$ or 12 from Eq. (29). Hence Eq. (29) is on the conservative side for gray cast iron gears if $k_{\tau}=2$ is assumed. Though it is anticipated that the stress concentration factor for ductile cast iron will be higher than that of gray cast iron, it will be conservative to treat ductile cast iron gear as a steel gear. Then Eq. (29) will be applicable. 